\title{
Use of ER/PR/HER2 subtypes in conjunction with the 2007 St Gallen Consensus Statement for early breast cancer
}

Katrina Bauer ${ }^{+1}$, Carol Parise ${ }^{\dagger 2}$ and Vincent Caggiano*+2

\begin{abstract}
Background: The 2007 St Gallen international expert consensus statement describes three risk categories and provides recommendations for treatment of early breast cancer. The set of recommendations on how to best treat primary breast cancer is recognized and used by clinicians worldwide. We now examine the variability of five-year survival of the 2007 St Gallen Risk Classifications utilizing the ER/PR/HER2 subtypes.
\end{abstract}

Methods: Using the population-based California Cancer Registry, 114,786 incident cases of Stages 1-3 invasive breast cancer diagnosed between 2000 and 2006 were identified. Cases were assigned to Low, Intermediate, or High Risk categories. Five-year-relative survival was computed for the three St Gallen risk categories and for the ER/PR/HER2 subtypes for further differentiation.

Results and Discussion: There were 9,124 (13\%) cases classified as Low Risk, 44,234 (65\%) cases as Intermediate Risk, and 14,340 (21\%) as High Risk. Within the Intermediate Risk group, 33,735 (76\%) were node-negative (Intermediate Risk 2) and 10,499 (24\%) were node-positive (Intermediate Risk 3). For the High Risk group, 6,149 (43\%) had 1 to 3 positive axillary lymph nodes (High Risk 4) and 8,191 (57\%) had four or more positive lymph nodes (High Risk 5).

Using five-year relative survival as the principal criterion, we found the following: a) There was very little difference between the Low Risk and Intermediate Risk categories; b) Use of the ER/PR/HER2 subtypes within the Intermediate and High Risk categories separated each into a group with better five-year survival (ER-positive) and a group with worse survival (ER-negative), irrespective of HER2-status; C) The heterogeneity of the High Risk category was most evident when one examined the ER/PR/HER2 subtypes with four or more positive axillary lymph nodes; (d) HER2positivity did not always translate to worse survival, as noted when one compared the triple positive subtype (ER+/ PR+/HER2+) to the triple negative subtype (ER-/PR-/HER2-); and (e) ER-negativity appeared to be a stronger predictor of poor survival than HER2-positivity.

Conclusion: The use of ER/PR/HER2 subtype highlights the marked heterogeneity of the Intermediate and High Risk categories of the 2007 St Gallen statements. The use of ER/PR/HER2 subtypes and correlation with molecular classification of breast cancer is recommended.

\section{Background}

The 2007 St Gallen international expert consensus statement described three risk categories and provided recommendations for treatment of early breast cancer [1]. Since the first publication of the consensus statements in

\footnotetext{
* Correspondence: caggiav@sutterhealth.org

2 Sutter Institute for Medical Research, 2801 Capitol Ave Suite 400, Sacramento CA, USA

+ Contributed equally

Full list of author information is available at the end of the article
}

1988 [2], now updated every two years, the set of recommendations on how to best treat primary breast cancer is recognized and used by clinicians worldwide.

Molecular classification is rapidly becoming the gold standard for complete characterization of breast cancer and the underlying technology has already led to generation of gene-profiling models to predict outcomes [3-5]. Despite these remarkable achievements, clinicians still rely on traditional tumor marker analysis for treatment decisions. We recently described the distribution and 
five-year survival of the subtypes of breast cancer based on estrogen receptor (ER), progesterone receptor (PR), and human epidermal growth factor receptor 2 (HER2) $[6,7]$, and found wide variation in survival especially among the HER2-positive group of patients. We now examine the variability of five-year survival of the $2007 \mathrm{St}$ Gallen Risk Classifications utilizing the ER/PR/HER2 subtypes.

\section{Methods}

Breast cancer cases used in these analyses were identified using the population-based California Cancer Registry (CCR). Cases are reported to the Cancer Surveillance Section of the California Department of Public Health from hospitals and any other facilities providing care or therapy to cancer patients residing in California [8].

For the current study, we identified 114,786 first primary cases of invasive breast cancer (ICDO-3 sites C50.0-C50.9) [9] diagnosed between January 1, 2000 and December 31, 2006, and reported to the CCR as of December 2008. This study period was selected because it is prior to the era when trastuzumab was routinely administered to women with early breast cancer that overexpressed HER2. Cases diagnosed outside of California, at autopsy, or from death certificates were excluded.

The CCR requires the collection of tumor marker information from the medical record on the status of ER and PR for breast cancers diagnosed on or after January 1 , 1990 and HER2 for breast cancers diagnosed on or after January 1, 1999. ER and PR status are recorded according to the pathologist's interpretation of assays. A tumor is considered to be ER negative and PR negative if less than $5 \%$ of tumor cell nuclei are immunoperoxidase positive in immunohistochemistry (IHC) assays. ER and PR status may also have been determined by examining cytosol protein (ER negative or PR negative if there are fewer than 3 or $5 \mathrm{fmol} / \mathrm{mg}$ of cytosol protein, respectively) HER2 was assessed through IHC or fluorescence in situ hybridization (FISH). IHC is scored on a qualitative scale based on staining intensity: 0 and $1+$ are negative, $2+$ is borderline, and $3+$ is positive. FISH is scored on a quantitative scale: less than 2 copies of the HER2 gene is negative and 2 or more copies is positive. Cases with complete tumor marker data were used in this study and were categorized into one of the eight distinct subtypes based on ER/PR/HER2 status of the tumor. Cases with unknown or borderline tumor marker status were excluded from these analyses [8].

Stage at diagnosis was collected from the patient's medical record and coded according to the American Joint Commission on Cancer (AJCC) Cancer Staging Manual $6^{\text {th }}$ edition [10]. The CCR collected Surveillance Epidemiology and End Results (SEER) Extent of Disease (EOD) for breast cancer cases diagnosed from 1988 through
December 2003 [11], and in 2004, began collecting Collaborative Staging data items [12]. EOD was converted to AJCC stage at diagnosis using SEER guidelines [13]. For these analyses, stage IV and cases with unknown stage were omitted. Tumor grade was collected from the medical record and coded according to ICDO-3 [9].

Treatment information available from the registry abstract was recorded as one of four possibilities: a) chemotherapy without endocrine therapy; b) endocrine therapy without chemotherapy; c) chemotherapy and endocrine therapy; d) no chemotherapy or endocrine therapy or unknown. Information about the use of specific anti-HER2 therapy was not available.

Cases were assigned to Low, Intermediate, or High Risk categories according to published criteria [1] with one exception. The extent of peritumoral vascular invasion was not available from the CCR's database and could not be utilized for determining the St Gallen risk stratification.

Counts and 5-year relative cumulative survival were calculated using SEER*Stat 6.1.4. The actuarial method was used for relative survival calculations. Five-year-relative survival was computed for the three St Gallen risk categories, and also for the ER/PR/HER2 subtypes to further differentiate the risk categories. Differences between survival curves were compared using the Z- test for comparison of relative survival rates [14].

\section{Results}

There were 114,786 incident cases of Stages 1-3 invasive breast cancer diagnosed between 2000 and 2006. After exclusion of 38,418 cases with at least one missing tumor marker there were 76,368 cases. An additional 8,670 were eliminated because they lacked age, size of tumor, stage, or grade resulting in 67,698 (59\%) cases available for survival analysis (Table 1 ). Table 2 shows the clinicopathologic breakdown of the cases included in the analysis.

The distribution of the ER/PR/HER2 subtypes within each risk category is shown in Table 3 and Figure 1 . There were 9,124 (13\%) cases classified as Low Risk, 44,234 (65\%) cases as Intermediate Risk, and 14,340 (21\%) as High Risk. Within the Intermediate Risk group, 33,735

\section{Table 1: Summary of cases included in the analysis.}

\begin{tabular}{lc}
$\begin{array}{l}\text { Cases with stages } 1-31^{\text {st }} \\
\text { primary invasive breast }\end{array}$ & 114,786 \\
$\begin{array}{l}\text { cancer } 2000-2006 \\
\text { Cases missing at least one }\end{array}$ & 38,418 \\
tumor marker & \\
$\begin{array}{l}\text { Cases missing age, tumor } \\
\text { size, stage, or grade }\end{array}$ & 8,670 \\
\hline $\begin{array}{l}\text { Total included in the } \\
\text { analysis }\end{array}$ & $\mathbf{6 7 , 6 9 8}$ \\
\hline
\end{tabular}


Table 2: Demographic and clinicopathologic characteristics for stages 1-3 first primary invasive breast cancer, $2000-2006$.

\begin{tabular}{|c|c|c|}
\hline & $\underline{\mathbf{n}}$ & $\underline{\%}$ \\
\hline \multicolumn{3}{|l|}{ Node Status } \\
\hline Node Negative & 42,859 & $63.3 \%$ \\
\hline 1-3 Nodes Positive & 16,648 & $24.6 \%$ \\
\hline$>3$ Nodes Positive & 8,191 & $12.1 \%$ \\
\hline \multicolumn{3}{|l|}{ Stage } \\
\hline 1 & 31,721 & $46.9 \%$ \\
\hline ॥ & 28,952 & $42.8 \%$ \\
\hline III & 7,025 & $10.4 \%$ \\
\hline \multicolumn{3}{|l|}{ Grade } \\
\hline Well differentiated; Grade I & 14,813 & $21.9 \%$ \\
\hline Moderately differentiated; Grade II & 28,406 & $42.0 \%$ \\
\hline Poorly differentiated; Grade III & 23,191 & $34.3 \%$ \\
\hline Undifferentiated; anaplastic; Grade IV & 1,288 & $1.9 \%$ \\
\hline \multicolumn{3}{|l|}{ ER/PR/HER2 Status } \\
\hline$+/+/+$ & 7,343 & $10.8 \%$ \\
\hline$+/+/-$ & 36,906 & $54.5 \%$ \\
\hline$+/-/+$ & 2,258 & $3.3 \%$ \\
\hline$+/-/-$ & 6,305 & $9.3 \%$ \\
\hline$-/+/+$ & 319 & $0.5 \%$ \\
\hline$-/-/+$ & 4,805 & $7.1 \%$ \\
\hline$-/+/-$ & 652 & $1.0 \%$ \\
\hline$-/-/-$ & 9,110 & $13.5 \%$ \\
\hline \multicolumn{3}{|l|}{ Tumor Size } \\
\hline$\leq 2 \mathrm{~cm}$ & 42,043 & $62.1 \%$ \\
\hline$>2 \mathrm{~cm}$ & 25,655 & $37.9 \%$ \\
\hline \multicolumn{3}{|l|}{ Race/Ethnicity } \\
\hline Non-Hispanic White & 47,016 & $69.4 \%$ \\
\hline Non-Hispanic Black & 3,606 & $5.3 \%$ \\
\hline Hispanic & 10,134 & $15.0 \%$ \\
\hline Asian/Pacific Islander & 6,942 & $10.3 \%$ \\
\hline \multicolumn{3}{|l|}{ Age } \\
\hline$\leq 45$ & 11,755 & $17.4 \%$ \\
\hline $46-69$ & 40,058 & $59.2 \%$ \\
\hline$\geq 70$ & 15,885 & $23.5 \%$ \\
\hline Total & 67,698 & \\
\hline
\end{tabular}


Table 3: Distribution of the ER/PR/HER2 subtypes by St Gallen risk category.

\begin{tabular}{|c|c|c|c|c|c|c|c|}
\hline & Low Risk & $\begin{array}{c}\text { Intermediate } \\
\text { Risk } 2\end{array}$ & $\begin{array}{c}\text { Intermediate } \\
\text { Risk } 3\end{array}$ & $\begin{array}{c}\text { High Risk } \\
4\end{array}$ & $\begin{array}{c}\text { High Risk } \\
5\end{array}$ & $n$ & $\%$ \\
\hline$+/+/+$ & 0 & 4,242 & 0 & 1,965 & 1,136 & 7,343 & 10.8 \\
\hline$+/+/-$ & 7,841 & 16,456 & 8,912 & 0 & 3,697 & 36,906 & 54.5 \\
\hline$+/-/+$ & 0 & 1,244 & 0 & 652 & 362 & 2,258 & 3.3 \\
\hline$+/-/-$ & 1,228 & 2,908 & 1,437 & 0 & 732 & 6,305 & 9.3 \\
\hline$-/+/+$ & 0 & 176 & 0 & 84 & 59 & 319 & 0.5 \\
\hline$-/-/+$ & 0 & 2,544 & 0 & 1,279 & 982 & 4,805 & 7.1 \\
\hline$-/+/-$ & 55 & 369 & 150 & 0 & 78 & 652 & 1.0 \\
\hline$-/-/-$ & 0 & 5,796 & 0 & 2,169 & 1,145 & 9,110 & 13.5 \\
\hline $\mathbf{n}$ & 9,124 & 33,735 & 10,499 & 6,149 & 8,191 & 67,698 & \\
\hline$\%$ & 13.5 & 49.8 & 15.5 & 9.1 & 12.1 & & \\
\hline
\end{tabular}

(76\%) were node-negative (Intermediate Risk 2) and 10,499 (24\%) were node-positive (Intermediate Risk 3). For the High Risk group, 6,149 (43\%) had 1 to 3 positive axillary lymph nodes (High Risk 4) and 8,191 (57\%) had four or more positive lymph nodes (High Risk 5).

Five-year relative survival curves revealed a statistically significant difference between the Low and both Intermediate Risk categories $(\mathrm{p}<0.001)$ (Figure 2). There was no statistically significant difference between the two Intermediate risk categories. The High Risk category is clearly separated from the Low and Intermediate Risk categories, and those with four or more positive lymph nodes (High Risk 5) have worse survival than those with 1 to 3 positive lymph nodes (High Risk 4) ( $<<0.001$ ).

When the St Gallen Risk categories were analyzed according to ER/PR/HER2 subtypes, no difference in survival was seen in the Low Risk group (not shown) but distinct differences were noted in the Intermediate Risk (Figure 3) and High Risk (Figure 4) categories. All ERpositive subtypes within the Intermediate Risk group, regardless of HER2 status, had excellent five-year relative survival (95\% or better), whereas all ER-negative subtypes had worse survival.

For the High Risk group, a similar ER-positive pattern was noted except for the ER+/PR-/HER2- subtype. When the Intermediate and High Risk categories were analyzed according to axillary lymph node status as well as ER/PR/ HER2 status, the ER+/PR-/HER2+ and ER+/PR-/HER2subtypes had equally excellent five-year relative survival within the node-negative group (Intermediate Risk 2) (p $=0.234)$, and the ER+/PR+/HER2- and ER+/PR-/HER2subtypes had significantly better survival than the ER-/ $\mathrm{PR}+$ /HER2- subtype within the node-positive group (Intermediate Risk 3), as seen in Figures 5 and 6 (p < 0.001 for both comparisons).
Within the High Risk category characterized by 1 to 3 positive nodes (High Risk 4), the ER+/PR+/HER2+ and ER+/PR-/HER2+ subtypes had excellent five-year survival whereas the remaining subtypes, all ER-negative, had significantly worse survival $(\mathrm{p}<0.02)$ (Figure 7). For those High Risk patients with four or more positive lymph nodes (High Risk 5), the best survival was seen in the $\mathrm{ER}+/ \mathrm{PR}+/ \mathrm{HER} 2+$ subtype and the worst survival in the ER-/PR-/HER2- subtype (Figure 8) (p < 0.001).

Treatment information is summarized in Table 4. Of the 4,717 cases within the Low Risk category known to have received some form of therapy, 4,019 (85\%) received only endocrine treatment (ET) and 698 (7\%) received chemotherapy and ET. For the Intermediate Risk category, 18,908 (66\%) received chemotherapy with or without ET, and 9,629 (34\%) received only ET. Within the High Risk category, 11,016 (94\%) received chemotherapy with or without ET, and 671 (6\%) received only ET.

\section{Discussion}

Clinicians have a variety of resources and guidelines to assist in treatment decisions for early breast cancer patients [15]. Adjuvant! Online [16], the guidelines of the National Comprehensive Cancer Network [17], the 21gene recurrence score [4], and the 70-gene expression assay [3], are well-known to most oncologists. The St Gallen Consensus Statements, however, remain a valuable tool, especially in Europe, perhaps because of its simplicity and ease of risk determination. Successive St Gallen conferences since 1988 have produced treatment guidance based on available evidence and expert opinion for the therapy of early breast cancer patients outside clinical trials. Various iterations of the St Gallen Consensus recommendations have been validated and compliance with recommendations for systemic therapy has 


\begin{tabular}{|c|c|c|c|c|c|}
\hline Subtype & Low & Intermediate & & & \\
\hline$+/+/+$ & --- & 4,242 & & & \\
\hline$+/+1-$ & 7,841 & 25,368 & & & \\
\hline$+/-/+$ & --- & 1,244 & & & \\
\hline$+/-/-$ & 1,228 & 4,345 & & & \\
\hline$-/+/+$ & --- & 176 & & & \\
\hline$-/-/+$ & --- & 2,544 & & & \\
\hline$-|+|-$ & 55 & 519 & & & \\
\hline$-/-/-$ & --- & 5,796 & & & \\
\hline Total & 9,124 & 44,234 & & & \\
\hline Subtype & & Node Negative & Nod & $(1-3)$ & Node Positive $(>3)$ \\
\hline$+/+/+$ & & 4,242 & --- & 1,965 & 1,136 \\
\hline$+/+1-$ & & 16,456 & 8,912 & --- & 3,697 \\
\hline$+/-/+$ & & 1,244 & --- & 652 & 362 \\
\hline$+/-/-$ & & 2,908 & 1,437 & --- & 732 \\
\hline$-/+/+$ & & 176 & --- & 84 & 59 \\
\hline$-/-/+$ & & 2,544 & --- & 1,279 & 982 \\
\hline$-/+1-$ & & 369 & 150 & --- & 78 \\
\hline$-/-/-$ & $\downarrow$ & 5,796 & --- & 2,169 & 1,145 \\
\hline Total & 9,124 & 33,735 & 10,499 & 6,149 & 8,171 \\
\hline \multirow[t]{2}{*}{ Risk level } & Low & \multirow{2}{*}{\multicolumn{2}{|c|}{$\begin{array}{l}\text { Intermediate } \\
\end{array}$}} & \multicolumn{2}{|r|}{ High } \\
\hline & 1 & & & 4 & 5 \\
\hline
\end{tabular}

been shown to improve survival of women with nodenegative breast cancer, refinements have been suggested [18-24] and some shortcomings have been described $[25,26]$.

Our initial CCR investigations of triple negative breast cancer $[27,28]$ prompted us to examine all newly diagnosed breast cancer patients using ER/PR/HER2 subtype as a surrogate for the molecular classification [6,7]. We were struck by the wide variation in five-year survival based on ER/PR/HER2, the marked heterogeneity of HER2-positive cancers, and the excellent survival of patients with ER-positive cancers irrespective of HER2 status. Indeed, we found the ER-positive/PR-positive/ HER2-positive subset of patients to have a five-year relative survival of $91.3 \%$ whereas the ER-negative/PR-negative/HER2-positive subset to have a $75.9 \%$ survival [7]. Clearly, not all HER2-positive breast cancers are bad actors. We therefore decided to explore this more fully and determine the ER/PR/HER2 subtypes within the context of the St Gallen risk categories.

The Intermediate Risk is the largest of the three risk categories defined in the 2007 St Gallen statement, constituting $65.3 \%$ of all patients, the Low Risk the smallest (13.4\%) and the High Risk next at $21.3 \%$. Based solely on five-year relative survival, there is not much difference between Low and Intermediate Risk, but clear separation of the High Risk category is noted.

Use of the ER/PR/HER2 subtypes clearly separates the Intermediate Risk category into two distinct groups, one with better five-year survival (all ER-positive) and one with worse survival (all ER-negative). This separation persists for the node-negative subgroup (Intermediate Risk 2) as well as the node-positive subgroup (Intermediate Risk 3), although in this latter subgroup the ER-/PR+/ HER2- subtype is rather small. The existence of the ER-/ $\mathrm{PR}+$ subtypes is controversial [29,30] although some 


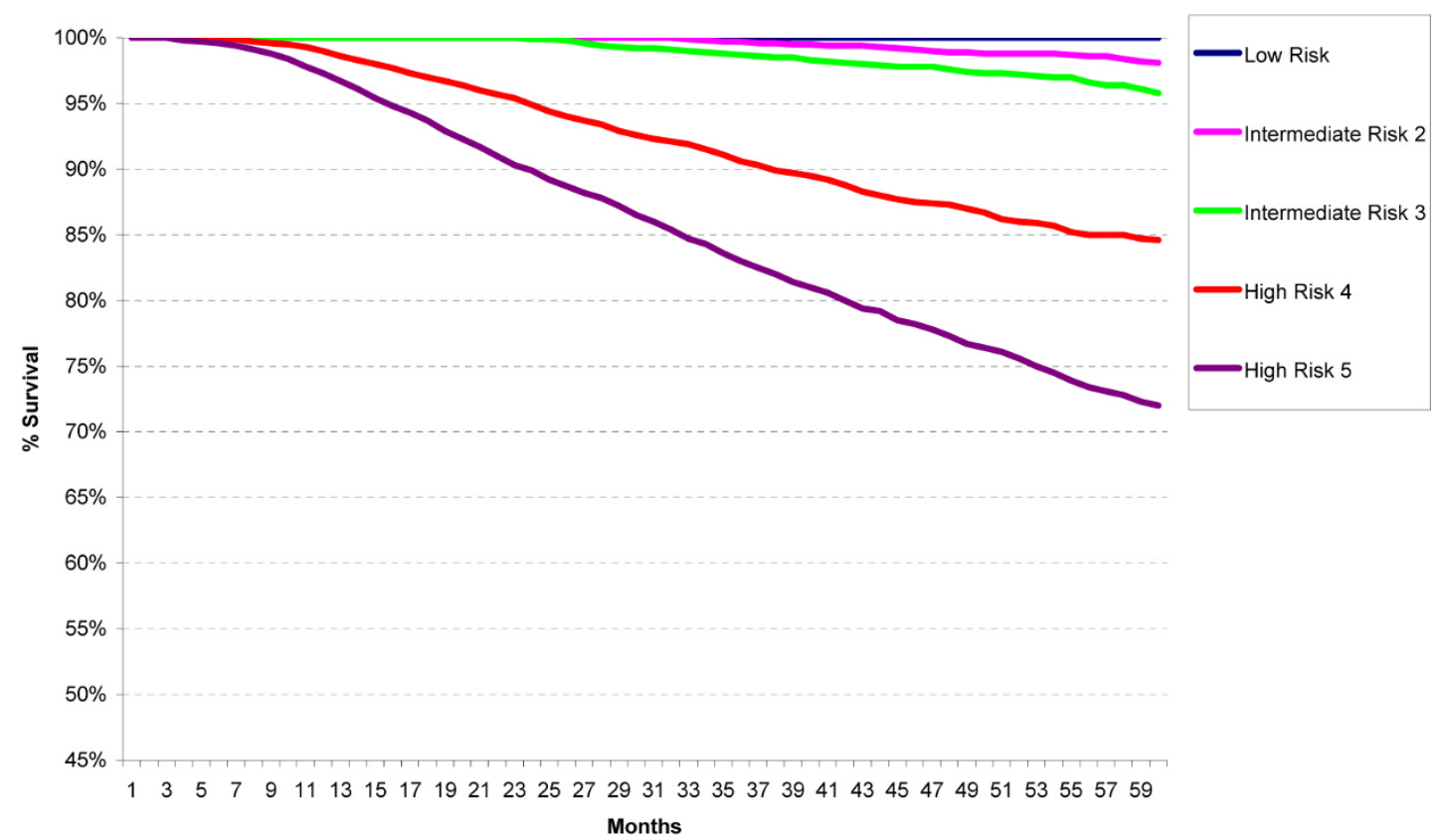

Figure 2 Five-year relative survival of low, intermediate, and high risk St Gallen categories for first primary invasive breast cancers in California, 2000-2006

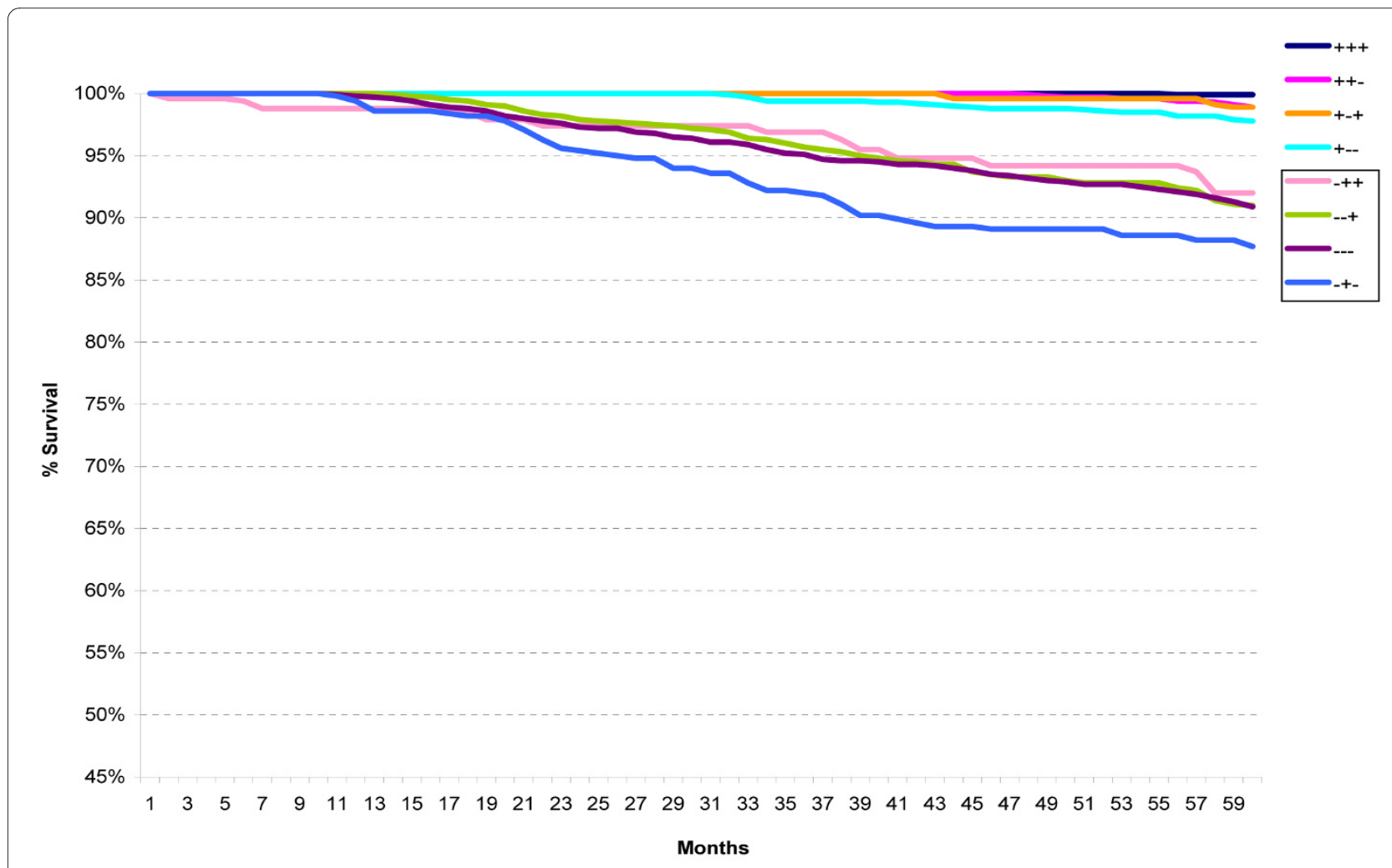

Figure 3 Five-year relative survival for all cases within the St Gallen intermediate risk group according to the ER/PR/HER2 subtypes. 


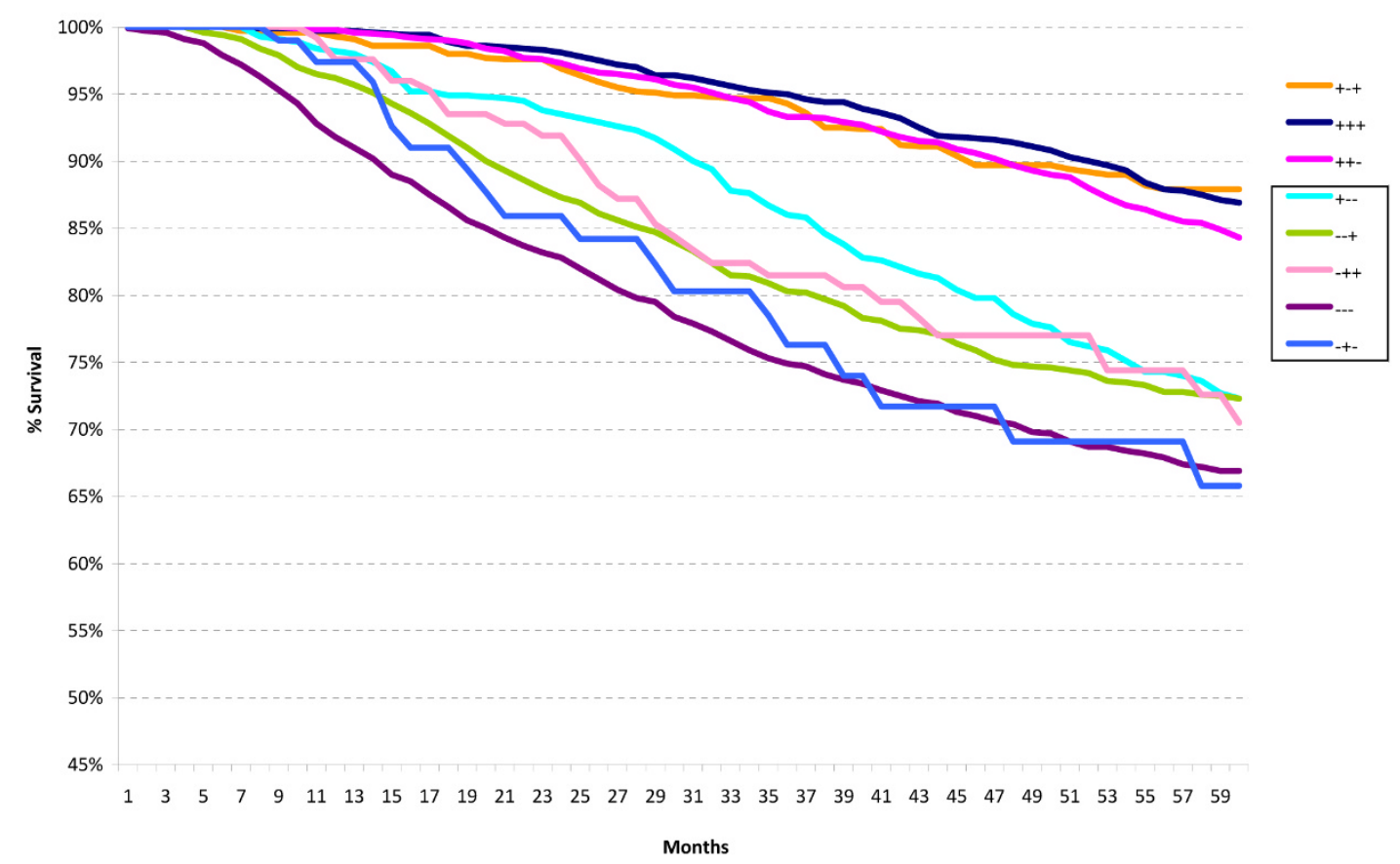

Figure 4 Five-year relative survival for all cases within the St Gallen high risk group according to the ER/PR/HER2 subtypes.

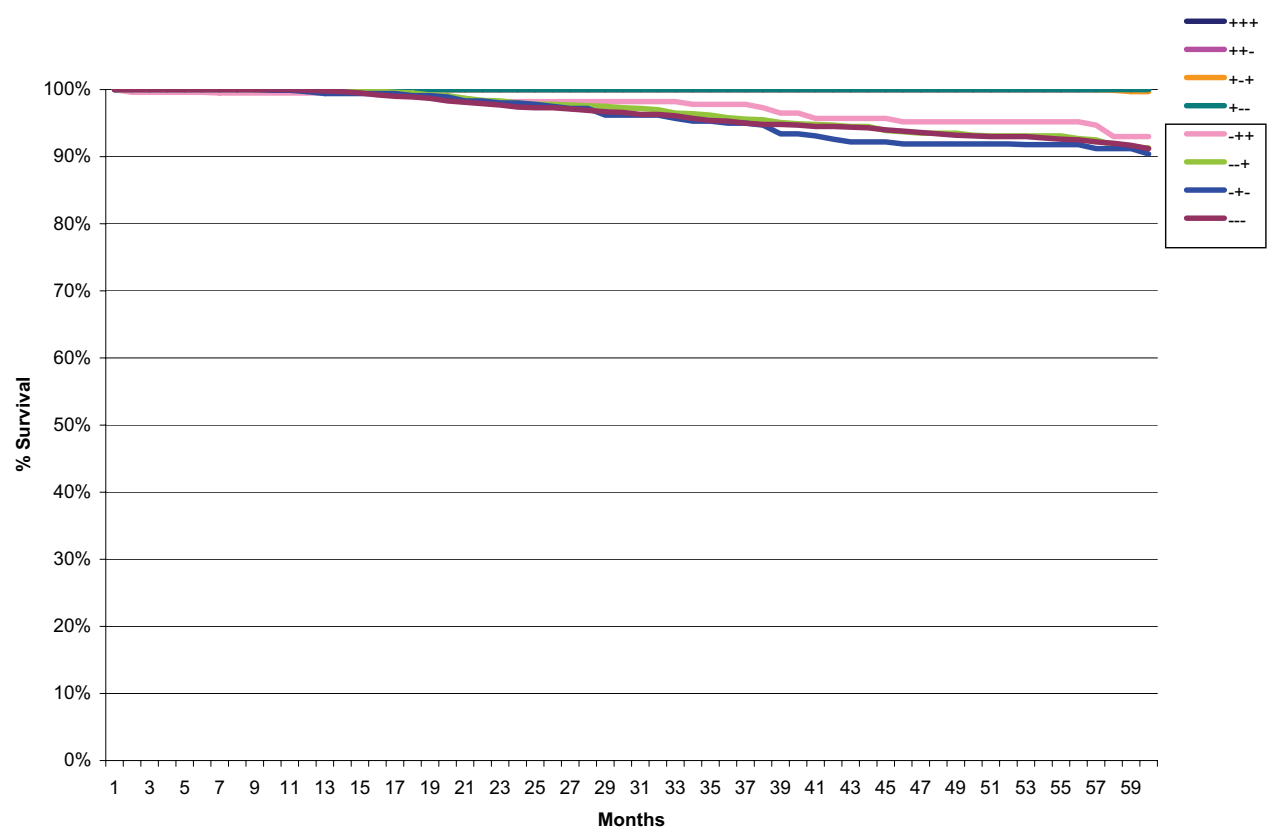

Figure 5 Five-year relative survival for node-negative cases within the St Gallen intermediate risk group (intermediate risk 2) according to the ER/PR/HER2 subtypes. 


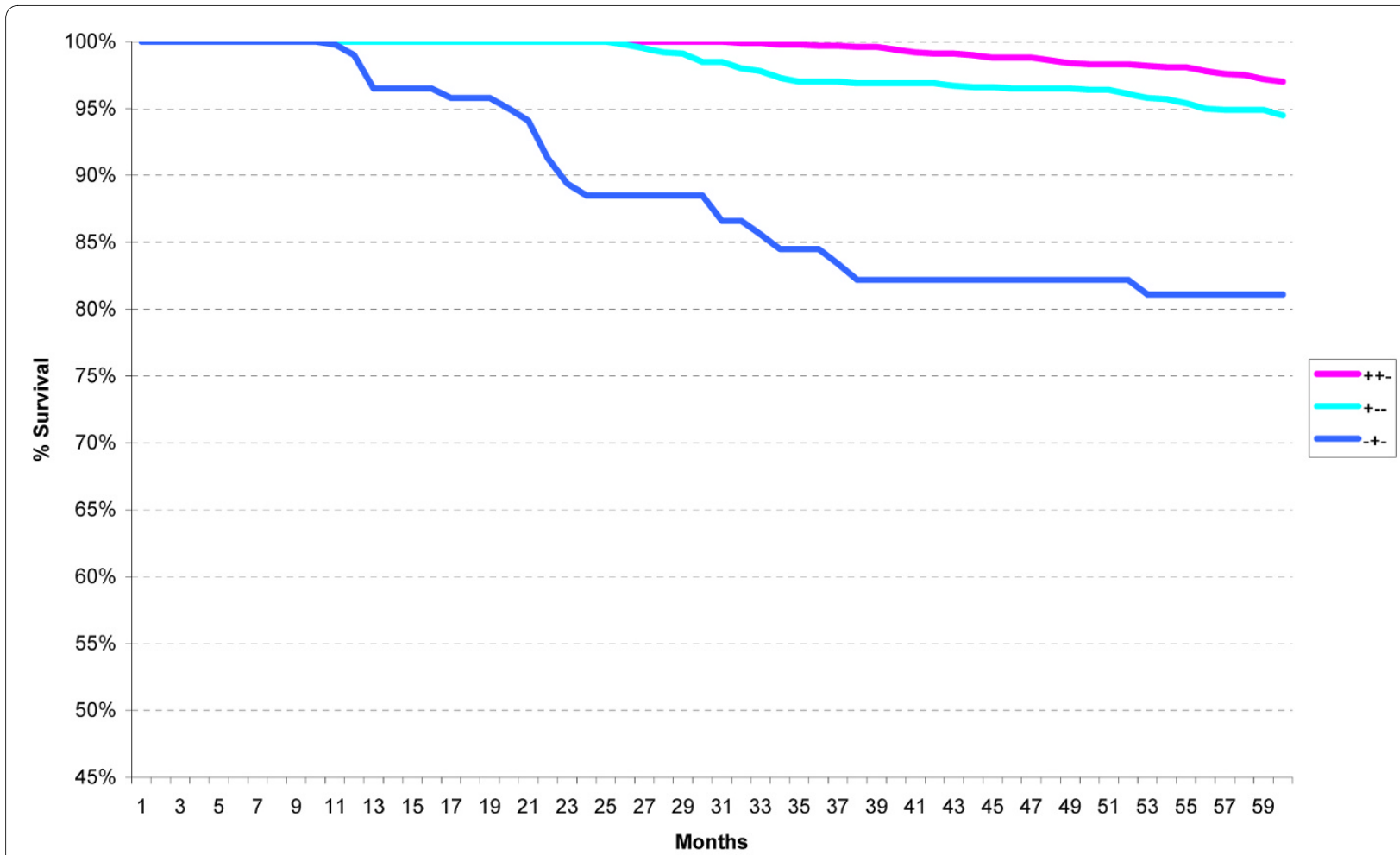

Figure 6 Five-year relative survival for node-positive cases within the St Gallen intermediate risk group (intermediate risk 3) according to the ER/PR/HER2 subtypes.

believe it is a distinctive subtype with a poor prognosis [31]. Our results, while not definitive in any sense, would tend to agree with this latter interpretation.

Marked variation in five-year survival is noted within the High Risk category, both for the subgroups with 1-3 positive axillary lymph nodes (High Risk 4 ) and $>3$ positive axillary lymph nodes (High Risk 5). The widest variation in five-year survival is seen for this latter subgroup, ranging from the triple positive subtype $(E R+/ P R+/$ HER2+) at $83 \%$ to the triple negative subtype (ER-/PR-/ HER2-) at $48 \%$. Clearly, there are different levels of risk. Once again, ER-positive subtypes have better survival than ER-negative subtypes, regardless of HER2 status.

That the 2007 St Gallen risk categories are useful for therapy guidance is evident from the limited treatment analysis, with $85 \%$ within Low Risk category receiving only ET, and $94 \%$ within High Risk category receiving chemotherapy with or without ET. However, our study has shown that, using five-year relative survival as the single principal criterion, (a) there is very little difference between Low Risk and Intermediate Risk categories, (b) use of the ER/PR/HER2 subtypes within the Intermediate and High Risk categories separates each into a group with better five-year survival (ER-positive) and a group with worse survival (ER-negative), irrespective of HER2-status, (c) the heterogeneity of the High Risk category is most evident when one examines the ER/PR/HER2 subtypes with four or more positive axillary lymph nodes, (d) HER2-positivity, per se, does not always translate to a worse survival, as noted when one compares the triple positive subtype (ER+/PR+/HER2+) to the triple negative subtype (ER-/PR-/HER2-), and (e) ER-negativity appears to be a stronger predictor of poor survival than HER2positivity.

The 2009 St Gallen conference proposed "a radically different treatment selection algorithm for the management of early breast cancer" and abandoned the three risk categories [32]. Instead, the threshold for indication of each systemic treatment modality was outlined, and two situations were recognized in which the decision to use adjuvant chemotherapy was relatively clear-cut, i.e., for patients with triple negative breast cancer and for patients with HER2-positive breast cancer. The present study once again confirms the poor survival of the triple negative subtype and the heterogeneity of the HER2-positive group of patients $[7,27]$. Although combined endocrine therapy in addition to anti-HER2 therapy without chemotherapy in strongly ER-positive, HER2-positive patients is logical but unproven [32], our survival results for the HER2-positive subtypes within the Intermediate and High Risk categories suggest an opportunity for just such a randomized clinical trial utilizing traditional clini- 


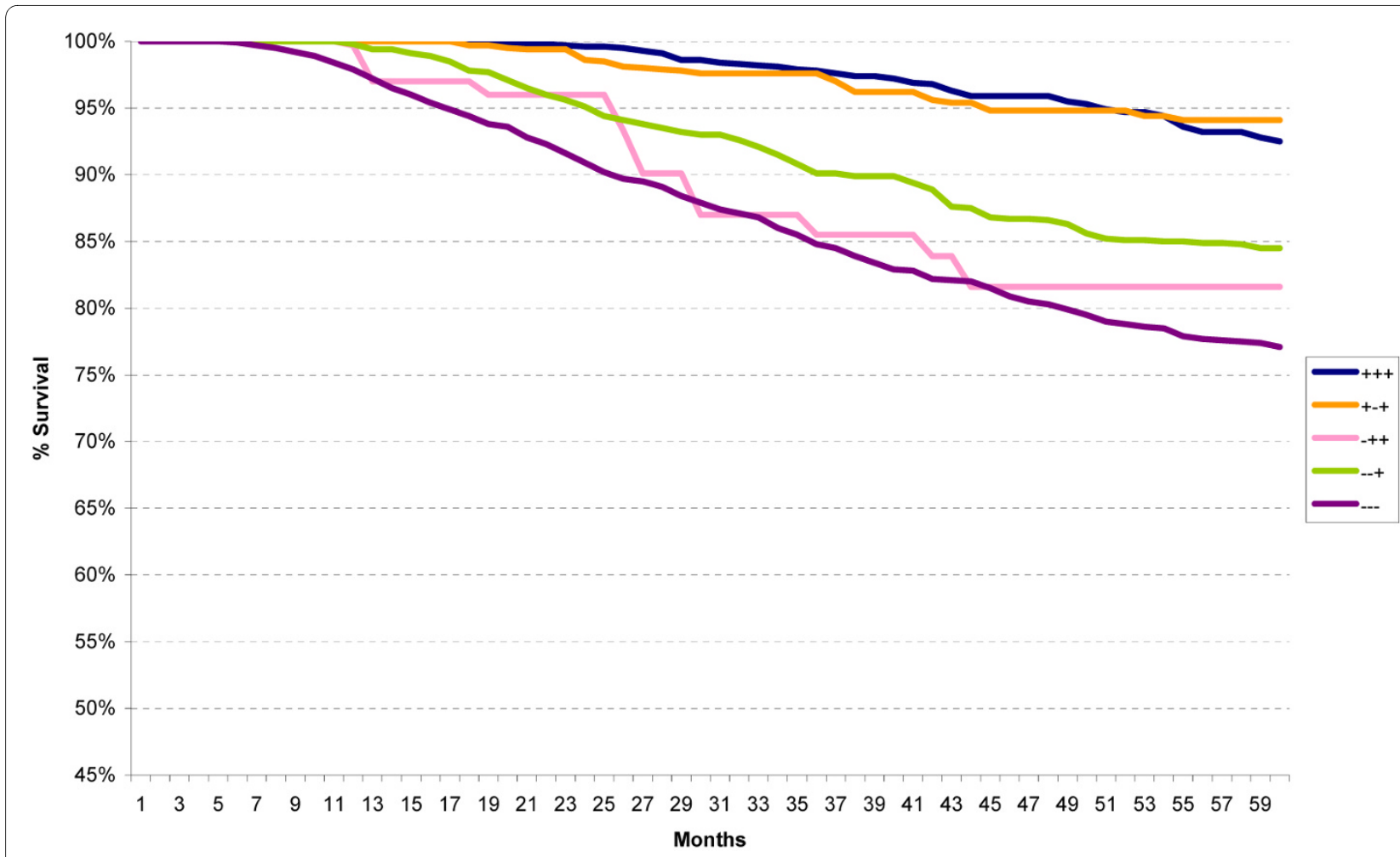

Figure 7 Five-year relative survival for node positive cases with 1-3 lymph nodes within the St Gallen high risk group (high risk 4) according to the ER/PR/HER2 subtypes

copathological factors, tumor markers, and gene expression profiling assays.

In a departure from the previous conference, the panel of the 2009 St Gallen meeting also supported the use of a validated multigene-profiling assay, if readily available, as an adjunct to high quality phenotyping of breast cancer in cases in which the indication for adjuvant chemotherapy remains uncertain. We are in agreement with this recommendation, and further urge use of the ER/PR/HER2 subtype or phenotype expression as a surrogate, albeit imperfect, for the molecular classification of breast cancer $[33,34]$. Correlation of the ER/PR/HER2 subtypes with gene-profiling assays makes good clinical sense. We suggest avoidance of the phrase "ER and/or PR positive".

Although we studied a large, racially diverse group of breast cancer patients, we recognize the limitations of this type of population-based registry investigation. Histologic grading of tumors, as well as tests for ER, PR, and HER2 were performed by a wide variety of laboratories without central review. Only $59 \%$ of the original cohort of patients was found to have complete clinicopathological factors. Of the 38,418 cases found lacking at least one tumor marker, the majority (86\%) were missing HER2. The exclusion of subjects without ER or PR results has been noted in other population-based cancer registry studies and our findings are similar [35-37]. Missing HER2 results have been described in our previous publications $[27,28]$. The St Gallen risk categories were applied retrospectively. Peritumoral vascular invasion was not recorded in the cancer registry abstract and could not be used for determination of the St Gallen risk categories. It is not entirely clear how this affects the risk categories. In a recent study, the adverse prognostic impact of peritumoral vascular invasion was limited to receptor-negative tumors regardless of chemotherapy [38]. Lastly, treatment information was minimal and generic in nature. Of the subjects known to have received some form of adjuvant therapy, the majority of ER-positive and ER-negative patients received endocrine therapy and chemotherapy, respectively. However, start and stop dates of treatments, and the specific forms of endocrine and chemotherapy were not available in the registry data. Anti-HER2 therapy was not recorded in the registry abstract. It should be noted that, in the United States, trastuzumab was approved for adjuvant treatment of breast cancer patients in November 2006, and thus the lack of anti-HER2 treatment data may have only a slight confounding effect. Lastly, patient accrual was from 2000 to 2006 and ana- 


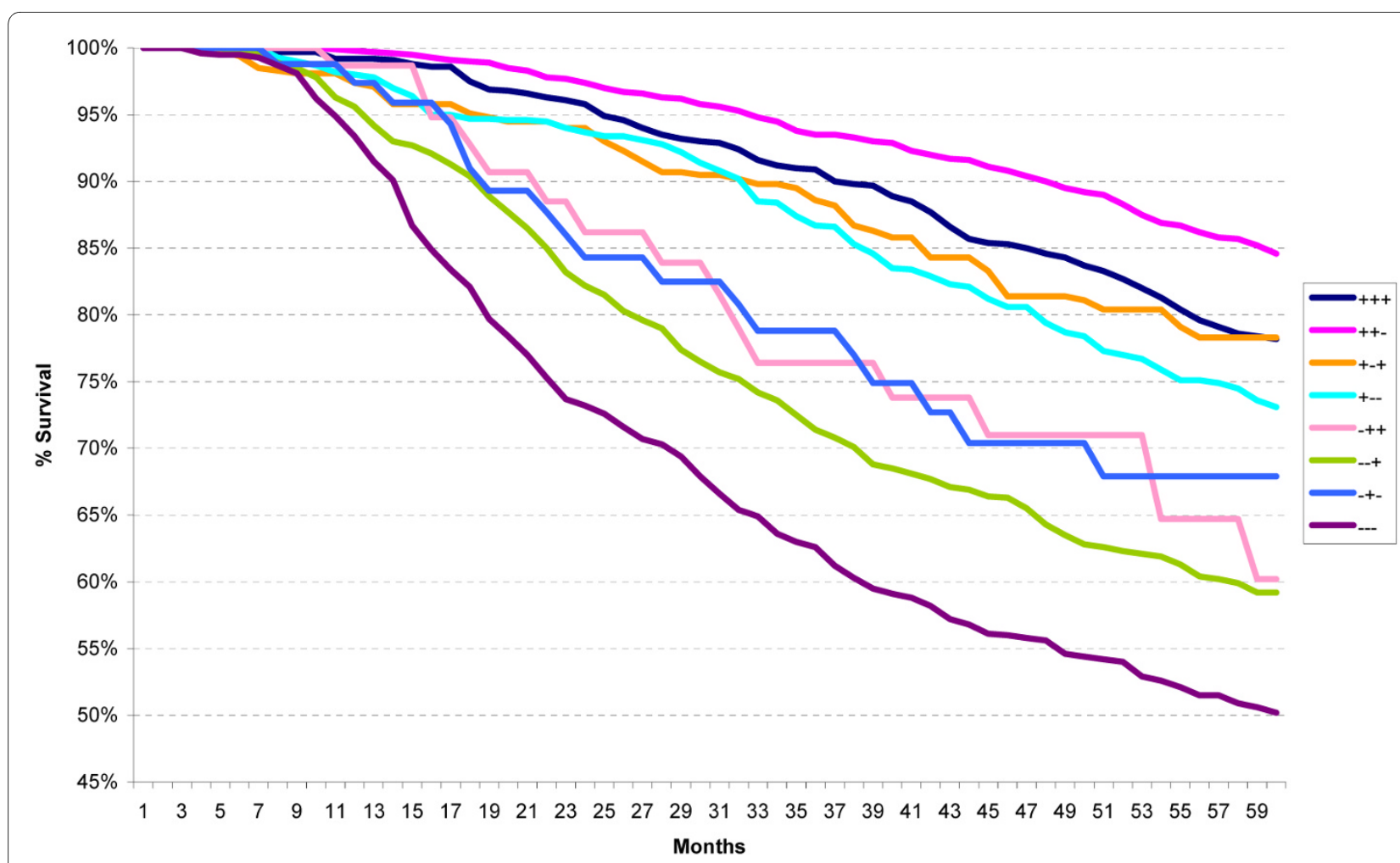

Figure 8 Five-year relative survival for node positive cases with $>3$ lymph nodes within the St Gallen high risk group (high risk 5) according to the ER/PR/HER2 subtypes.

lyzed as of December 2008. We recognize that many patients were only at risk for two years and that many low risk patients may relapse after five years. Continued follow-up and analysis is planned.

Despite these shortcomings, we believe our study is of value because of the large number of breast cancer patients examined, reflecting real-world experience of a statewide cancer registry in an ethnically diverse population. We have shown how the use of ER/PR/HER2 subtype or phenotype expression highlights the marked heterogeneity of the Intermediate and High Risk categories of the 2007 St Gallen statements. We welcome the use of the molecular classification of breast cancer and gene-profiling assays. Further, we believe it is prudent to correlate molecular findings with less expensive techniques such as the use of ER/PR/HER2 subtypes and immunohistochemical (IHC) profiles, the so-called "Poor Man's IHC definitions of microarray-based intrinsic subtypes" [34].

\section{Conclusion}

The use of ER/PR/HER2 subtype highlights the marked heterogeneity of the Intermediate and High Risk categories of the 2007 St Gallen statements. The use of ER/PR/ HER2 subtypes and correlation with molecular classification of breast cancer is recommended.

Table 4: Differences in use of chemotherapy and endocrine therapy (ET) among the St Gallen risk categories.

\begin{tabular}{lrrr}
\hline & Low & Intermediate & High \\
\hline Chemotherapy without ET & & 12,429 & 8,007 \\
ET without chemotherapy & 349 & 9,629 & 671 \\
Chemotherapy + ET & 4,019 & 6,479 & 3,009 \\
None or Unknown & 349 & 15,697 & 2,653 \\
& 4,407 & & $\mathbf{4 4 , 2 3 4}$ \\
\hline Total & $\mathbf{9 , 1 2 4}$ & $\mathbf{4 4 0}$ \\
\hline
\end{tabular}




\section{Competing interests}

The authors declare that they have no competing interests.

\section{Authors' contributions}

$\mathrm{CP}$ and VC conceived the idea for the study and interpreted the data. KB obtained the data from the California Cancer Registry and conducted the statistical analysis. All three authors contributed to the writing and have read and approved the final manuscript.

\section{Acknowledgements}

This study was funded by a grant from the Sutter Institute for Medical Research. The collection of cancer incidence data used in this study was supported by the California Department of Public Health as part of the statewide cancer reporting program mandated by California Health and Safety Code Section 103885; the National Cancer Institute's Surveillance, Epidemiology and End Results Program under contract N01-PC-35136 awarded to the Northern California Cancer Center, contract N01-PC-35139 awarded to the University of Southern California, and contract N01-PC-54404 awarded to the Public Health Institute; and the Centers for Disease Control and Prevention's National Program of Cancer Registries, under agreement 1U58DP00807-01 awarded to the Public Health Institute. The ideas and opinions expressed herein are those of the author(s) and endorsement by the State of California, Department of Public Health the National Cancer Institute, and the Centers for Disease Control and Prevention or their Contractors and Subcontractors is not intended nor should be inferred.

The authors would like to thank Sharon Babcock and Theresa Johnson at the Sutter Resource Library for their assistance with this study.

\section{Author Details}

${ }^{1}$ California Cancer Registry, California Department of Public Health, Public Health Institute, Sacramento CA, USA and 2 Sutter Institute for Medical Research, 2801 Capitol Ave Suite 400, Sacramento CA, USA

Received: 20 November 2009 Accepted: 21 May 2010 Published: 21 May 2010

\section{References}

1. Goldhirsch A, Wood WC, Gelber RD, Coates AS, Thurlimann B, Senn HJ: Progress and promise: highlights of the international expert consensus on the primary therapy of early breast cancer 2007. Ann Oncol 2007, 18(7):1133-1144.

2. Glick JH: Meeting highlights: adjuvant therapy for breast cancer. J Nat/ Cancer Inst 1988, 80(7):471-475.

3. Vijver MJ van de, He YD, van't Veer LJ, Dai H, Hart AA, Voskuil DW, Schreiber GJ, Peterse JL, Roberts C, Marton MJ, et al:: A gene-expression signature as a predictor of survival in breast cancer. N Engl J Med 2002, 347(25):1999-2009

4. Paik S, Shak S, Tang G, Kim C, Baker J, Cronin M, Baehner FL, Walker MG Watson D, Park T, et al: A multigene assay to predict recurrence of tamoxifen-treated, node-negative breast cancer. N Engl J Med 2004, 351(27):2817-2826.

5. Acharya CR, Hsu DS, Anders CK, Anguiano A, Salter KH, Walters KS, Redman RC, Tuchman SA, Moylan CA, Mukherjee S, et al:: Gene expression signatures, clinicopathological features, and individualized therapy in breast cancer. JAMA 2008, 299(13):1574-1587.

6. Parise C, Brown M, Bauer K, Caggiano V: Variation among the ER, PR, and HER2 breast cancer subtypes in California. Breast Cancer Symposium: 2007; San Francisco 2007.

7. Parise CA, Bauer KR, Brown MM, Caggiano V: Breast Cancer Subtypes as Defined by the Estrogen Receptor (ER), Progesterone Receptor (PR), and the Human Epidermal Growth Factor Receptor 2 (HER2) among Women with Invasive Breast Cancer in California, 1999-2004. Breast J 2009, 15(6):593-602.

8. Cancer Reporting in California:Abstracting and Coding Procedures for Hospitals, California Cancer Reporting System Standards. In California Cancer Registry Data Standards and Quality Control Unit Volume I. California Department of Public Health: Cancer Surveillance and Research Branch, Sacramento, CA; 2009

9. Fritz AG: International classification of diseases for oncology: ICD-O. Volume vi. 3rd edition. Geneva: World Health Organization, Geneva; 2000:239
10. Greene FL, American Joint Committee on Cancer ACS: AJCC Cancer Staging Manual. 6th edition. New York: Springer-Verlag; 2002.

11. SEER Extent of Disease 1998. Codes and Coding Instructions. 3rd edition. Bethesda, MD: National Cancer Institute, National Institutes of Health, Bethesda MD; 1998.

12. Collaborative Staging Task Force of the American Joint Commission on Cancer. Collaborative Staging Manual and Coding Instructions, Version 01.03.00. U.S. Department of Health and Human Services, Bethesda, MD; 2004

13. Seiffert JE: SEER Program Comparative Staging Guide for Cancer. Bethesda, MD: Cancer Statistics Branch Surveillance Program, Division of Cancer Prevention and Control (DCPC). National Cancer Institute (U.S.) Bethesda MD; 1993.

14. Brown CC: The statistical comparison of relative survival rates. Biometrics 1983, 39(4):941-948.

15. Cufer $\mathrm{T}$ : Which tools can I use in daily clinical practice to improve tailoring of treatment for breast cancer? The 2007 St Gallen guidelines and/or Adjuvant! Online. Ann Oncol 2008, 19(Suppl 7):vii. 41-45

16. Adjuvant! Online [http://www.adjuvantonline.com/index.jsp]. Accessed on: January 10, 2009

17. National Comprehensive Cancer Network [http://www.ncen.org/ index.asp]. Accessed on: January 10, 2009

18. Iwamoto E, Fukutomi T, Akashi-Tanaka S: Validation and problems of StGallen recommendations of adjuvant therapy for node-negative invasive breast cancer in Japanese patients. Jpn J Clin Oncol 2001, 31(6):259-262.

19. Colomer R, Vinas $G$, Beltran $M$, Izquierdo A, Lluch A, Llombart-Cussac A, Alba E, Munarriz B, Martin M: Validation of the 2001 St Gallen risk categories for node-negative breast cancer using a database from the Spanish Breast Cancer Research Group (GEICAM). J Clin Oncol 2004, 22(5):961-962.

20. Hebert-Croteau N, Brisson J, Latreille J, Rivard M, Abdelaziz N, Martin G: Compliance with consensus recommendations for systemic therapy is associated with improved survival of women with node-negative breast cancer. J Clin Oncol 2004, 22(18):3685-3693.

21. Yau TK, Soong IS, Chan K, Chang A, Sze H, Yeung MW, Tung R, Lau S, Lee A: Evaluation of the prognostic value of $2005 \mathrm{St}$ Gallen risk categories for operated breast cancers in Hong Kong. Breast 2008, 17(1):58-63.

22. Sun JM, Han W, Im SA, Kim TY, Park IA, Noh DY, Heo DS, Bang YJ, Choe KJ, Kim NK: A combination of HER-2 status and the St. Gallen classification provides useful information on prognosis in lymph node-negative breast carcinoma. Cancer 2004, 101(11):2516-2522.

23. Jung SY, Han W, Lee JW, Ko E, Kim E, Yu JH, Moon HG, Park IA, Oh DY, Im SA, et al:: Ki-67 expression gives additional prognostic information on St. Gallen 2007 and Adjuvant! Online risk categories in early breast cancer. Ann Surg Oncol 2009, 16(5):1112-1121.

24. Schmidt M, Victor A, Bratzel D, Boehm D, Cotarelo C, Lebrecht A, Siggelkow W, Hengstler JG, Elsasser A, Gehrmann M, et al:: Long-term outcome prediction by clinicopathological risk classification algorithms in node-negative breast cancer--comparison between Adjuvant!, St Gallen, and a novel risk algorithm used in the prospective randomized Node-Negative-Breast Cancer-3 (NNBC-3) trial. Ann Oncol 2009, 20(2):258-264

25. Boyages J, Chua B, Taylor R, Bilous M, Salisbury E, Wilcken N, Ung O: Use of the St Gallen classification for patients with node-negative breast cancer may lead to overuse of adjuvant chemotherapy. Br J Surg 2002, 89(6):789-796.

26. Boyages J, Taylor R, Chua B, Ung O, Bilous M, Salisbury E, Wilcken N: A risk index for early node-negative breast cancer. Br J Surg 2006, 93(5):564-571.

27. Bauer KR, Brown M, Cress RD, Parise CA, Caggiano V: Descriptive analysis of estrogen receptor (ER)-negative, progesterone receptor (PR)negative, and HER2-negative invasive breast cancer, the so-called triple-negative phenotype: a population-based study from the California cancer Registry. Cancer 2007, 109(9):1721-1728.

28. Brown M, Tsodikov A, Bauer KR, Parise CA, Caggiano V: The role of human epidermal growth factor receptor 2 in the survival of women with estrogen and progesterone receptor-negative, invasive breast cancer: the California Cancer Registry, 1999-2004. Cancer 2008, 112(4):737-747.

29. De Maeyer L, Van Limbergen E, De Nys K, Moerman P, Pochet N, Hendrickx W, Wildiers H, Paridaens R, Smeets A, Christiaens MR, et al.: Does estrogen 
receptor negative/progesterone receptor positive breast carcinoma exist? J Clin Oncol 2008, 26(2):335-336. author reply 336-338

30. Ibrahim M, Dodson A, Barnett S, Fish D, Jasani B, Miller K: Potential for false-positive staining with a rabbit monoclonal antibody to progesterone receptor (SP2): findings of the UK National External Quality Assessment Scheme for Immunocytochemistry and FISH highlight the need for correct validation of antibodies on introduction to the laboratory. Am J Clin Pathol 2008, 129(3):398-409.

31. Rakha EA, El-Sayed ME, Green AR, Paish EC, Powe DG, Gee J, Nicholson RI, Lee AH, Robertson JF, Ellis IO: Biologic and clinical characteristics of breast cancer with single hormone receptor positive phenotype. J Clin Oncol 2007, 25(30):4772-4778

32. Goldhirsch A, Ingle JN, Gelber RD, Coates AS, Thurlimann B, Senn HJ: Thresholds for therapies: highlights of the St Gallen International Expert Consensus on the primary therapy of early breast cancer 2009. Ann Oncol 2009, 20(8):1319-1329.

33. Carey LA, Perou CM, Livasy CA, Dressler LG, Cowan D, Conway K, Karaca G, Troester MA, Tse CK, Edmiston S, et al:: Race, breast cancer subtypes, and survival in the Carolina Breast Cancer Study. JAMA 2006, 295(21):2492-2502

34. Linn SC, Van't Veer LJ: Clinical relevance of the triple-negative breast cancer concept: genetic basis and clinical utility of the concept. Eur J Cancer 2009, 45(Suppl 1):11-26.

35. $\mathrm{Li} \mathrm{Cl}$, Daling JR, Malone KE: Incidence of invasive breast cancer by hormone receptor status from 1992 to 1998. J Clin Oncol 2003, 21(1):28-34

36. Grann VR, Troxel AB, Zojwalla NJ, Jacobson JS, Hershman D, Neugut Al: Hormone receptor status and survival in a population-based cohort of patients with breast carcinoma. Cancer 2005, 103(11):2241-2251.

37. Dunnwald LK, Rossing MA, Li Cl: Hormone receptor status, tumor characteristics, and prognosis: a prospective cohort of breast cancer patients. Breast Cancer Res 2007, 9(1):R6.

38. Viale G, Giobbie-Hurder A, Gusterson BA, Maiorano E, Mastropasqua MG, Sonzogni A, Mallon E, Colleoni M, Castiglione-Gertsch M, Regan MM, et al.: Adverse prognostic value of peritumoral vascular invasion: is it abrogated by adequate endocrine adjuvant therapy? Results from two International Breast Cancer Study Group randomized trials of chemoendocrine adjuvant therapy for early breast cancer. Ann Oncol 2010, 21(2):245-254

\section{Pre-publication history}

The pre-publication history for this paper can be accessed here: http://www.biomedcentral.com/1471-2407/10/228/prepub

doi: $10.1186 / 1471-2407-10-228$

Cite this article as: Bauer et al., Use of ER/PR/HER2 subtypes in conjunction with the 2007 St Gallen Consensus Statement for early breast cancer BMC Cancer $2010,10.228$

Submit your next manuscript to BioMed Centra and take full advantage of:

- Convenient online submission

- Thorough peer review

- No space constraints or color figure charges

- Immediate publication on acceptance

- Inclusion in PubMed, CAS, Scopus and Google Scholar

- Research which is freely available for redistribution

Submit your manuscript at www.biomedcentral.com/submit
C Biomed Central 